\title{
How to Achieve the Take-off into Sustained Growth: A Case Study for Slovenia
}

\author{
Reinhard Neck $^{1}$ (D) Klaus Weyerstrass ${ }^{1,2}$. \\ Dmitri Blueschke ${ }^{1}$ - Boris Majcen ${ }^{3}$. \\ Andrej Srakar ${ }^{3,4}$ - Miroslav Verbič ${ }^{3,4}$
}

\begin{abstract}
In this paper, we show that successful policy aimed at enhancing economic growth in the long run must be based on policies which improve human capital and technological progress. This is applied to Slovenia, a small open economy in the European Union and the Euro Area. In particular, we investigate how fiscal policies should be designed to support economic growth without violating the European Union Stability and Growth Pact. Using the SLOPOL10 model, an econometric model of the Slovenian economy, we analyse the effects of different fiscal policies in Slovenia over the next few years by means of simulations. The fiscal policy multipliers of the Slovenian economy are small and short-lived, which renders demand-side expansionary fiscal policies inappropriate as a means of achieving higher growth. However, if an increase in government expenditures directly related to technological progress is implemented (such as better funding for tertiary education or subsidies for firms' investments in research and development), this can trigger a path of output which is permanently higher than that of the baseline simulation. Reducing income taxes and social security contributions has strong positive effects on employment. This result shows that the key to prosperity and sustained growth is investment in human capital and technology, also for a small open economy like Slovenia.
\end{abstract}

Keywords Macroeconomics $\cdot$ Stabilization policy $\cdot$ Fiscal policy $\cdot$ Tax policy $\cdot$ Public expenditures $\cdot$ Demand management $\cdot$ Supply side policies $\cdot$ Slovenia $\cdot$ Public debt

Electronic supplementary material The online version of this article (https://doi.org/10.1007/s11294-0189678-8) contains supplementary material, which is available to authorized users.

Reinhard Neck

reinhard.neck@uni-klu.ac.at

1 Department of Economics, Alpen-Adria-Universität Klagenfurt, Klagenfurt, Austria

2 Macroeconomics and Public Finance Group, Institute for Advanced Studies, Vienna, Austria

3 Institute for Economic Research, Ljubljana, Slovenia

4 Faculty of Economics, University of Ljubljana, Ljubljana, Slovenia 
JEL Classification $\mathrm{E} 62 \cdot \mathrm{E} 17 \cdot \mathrm{E} 37$

\section{Motivation}

The Great Recession, the financial and economic crisis from 2008 to 2010, and the ensuing "Euro crisis" in the European Union (EU) have left most European economies with significantly lower real gross domestic product (GDP) per capita and higher unemployment than before. Economic recovery is slow and the question is often raised as to whether economic policies can contribute to higher growth and employment. As monetary policy is conducted on a supranational level by the European Central Bank (ECB) for the countries of the Euro Area, fiscal policy is seen as the only instrument remaining to deal with weak growth and high unemployment at a national level. An additional problem stems from the relatively high level of sovereign debt in most European countries which, according to many observers, prevents expansionary fiscal policy measures such as aggressive increases in government expenditures or decreases in tax rates. The so-called "austerity policy" prescribed by the European Commission is also seen as one of the reasons for the weak performance of the Euro Area with respect to output and employment over the last few years. Keynesian policy measures are proposed increasingly frequently to deal with these problems.

The alleged trade-offs between growth and employment enhancing policies and the goal of budget consolidation have recently led policy makers in the "periphery" of the Euro Area to complain about the restrictions imposed by the "austerity"-oriented policy stance of the European Commission. In addition, as most of the economies involved are small open economies, there is also a trade-off between expansionary fiscal policy and problems with the external balance. Higher aggregate demand for such economies entails higher imports, and if the international competitiveness of such an economy is low, this leads to the piling up of external debt, with possible negative repercussions on domestic demand. Examining these possible trade-offs requires empirical analyses of the effectiveness of fiscal policies with respect to economic growth and employment especially for small open economies.

The Slovenian economy is a case in point for such an examination. Entering the EU in 2004, the same time as most of the countries from Central and Eastern Europe, Slovenia was the only country in former Yugoslavia to do so. It introduced the euro as legal tender as early as 2007. It is a prototype of a small open economy with strong trade and financial links to other economies in the Euro Area. Moreover, it is one of the few small open transition economies that was already in the Euro Area before the Great Recession. Although the economic development of Slovenia was successful in terms of GDP growth and a reduction in unemployment before the Great Recession, the country was severely hit by the Great Recession and the Euro crisis, due to its exposed international position and domestic government failures alike.

Here we examine the question as to whether Slovenia would benefit more from a demand or supply-side orientation of its fiscal policy with the help of an econometric model. We use the Slovenian Policy (SLOPOL) model, an 
econometric model of the Slovenian economy we constructed, to simulate the effects of various tax and spending policies on important macroeconomic variables as well as on the public debt level (see the online supplemental appendix for the dataset). We describe the macroeconometric model SLOPOL10, used for the empirical analysis, with more details of the model given in Weyerstrass et al. (2018). A forecast of the Slovenian macroeconomy for the years 2017 to 2030 obtained with the model is presented, which serves as the baseline solution for the policy simulation. The forecast implies moderate growth, decreasing unemployment and a rising public-debt-to-GDP in the medium run. It turns out that expenditure side budgetary measures with a strong supply-side content (especially research and development $(\mathrm{R} \& \mathrm{D})$ related spending and enhancement of human capital) will be most successful and effective at stabilizing Slovenian output, while tax policies exert more influence on employment. In both cases, demand-side effects are weak at best, while supply-side measures can be instrumental in obtaining sustainable growth and full employment.

\section{SLOPOL Model}

SLOPOL is a macroeconometric model of the small open economy of Slovenia. The current version, SLOPOL10, consists of 75 equations, of which 23 are behavioural and 52 are identities. In addition, the model contains 41 exogenous variables. The behavioural equations were estimated by ordinary least squares (OLS), except for the labour demand and supply equations, which were estimated as censored Tobit models. Almost all behavioural equations were specified in error correction form. The equations are based on quarterly data for the period 1995Q1 to $2015 \mathrm{Q} 4$.

The model is based on the aggregate supply-aggregate demand (AS-AD) framework. Hence, it contains equations for both the supply side and the demand side. Rigidities of wages and prices are taken into account. The model combines Keynesian and neoclassical elements, the former determining the short- and medium-run solutions in the sense that the model is demand-driven and persistent disequilibria in the goods and labour markets are possible.

On the supply side, in accordance with the approach applied by the European Commission for all EU member states (Havik et al. 2014), potential output is determined by a Cobb-Douglas production function with constant returns to scale. Potential GDP depends on trend employment, the capital stock and autonomous technical progress. Ex post, total factor productivity (TFP) is calculated as the Solow residual. In a second step, the trend of technical progress is determined by applying the Hodrick-Prescott (HP) filter. For simulations and forecasts, the trend of the TFP is explained in a behavioural equation. Technical progress is influenced by the proportion of people with tertiary education in the labour force, by the real investment ratio, i.e. gross fixed capital formation over GDP, and by lagged real government spending on R\&D.

On the demand side, private consumption, gross fixed capital formation, exports and imports are determined in behavioural equations. On the labour market, labour demand and supply are divided into the main age group (15 to 64 years) 
and older people (65 years and above). Labour demand (actual employment) is modelled via the employment rates of the two age groups, i.e. employment as a proportion of the relevant age groups. Both employment rates are influenced positively by real GDP, negatively by the real net wage and additionally by the wedge between the gross and the net wage. Labour supply is modelled via the proportion of the labour force of the two age groups in the total population. It depends positively on the real net wage and negatively on the wedge between the gross and the net wage.

In the wage-price system, gross wages, the consumer price index (CPI) and various deflators are determined. On the money market, the short-term interest rate, the long-term interest rate and the real effective exchange rate are determined. The government sector block contains equations for social security revenues, profit taxes, value added tax (VAT) revenues, interest payments on public debt, and other revenues and expenditures. The following fiscal policy instruments are considered: government consumption, transfers to private households, public investment in machinery and construction, government expenditures on $R \& D$, the VAT rate, the personal income tax rate, and the social security contribution rate. In addition, we treat the proportion of the labour force with tertiary education as a policy instrument, though it is only controlled indirectly by the government. A more detailed description of the model is presented in Weyerstrass et al. (2018).

\section{Medium-Run Projection of the Slovenian Economy}

The focus of this paper lies on an analysis of the relative effectiveness of spending and tax policies in Slovenia during the period 2017 to 2030. As we are interested in comparing the effects of these fiscal policy measures with the trajectory of the Slovenian economy without such discretionary policies, we first have to determine a baseline simulation. Since the model is based on data until 2015, our forecast has to start in 2016. To this end, we have to make assumptions about the future development of all exogenous variables in the model. These can be divided into international variables (world trade, the oil price and Euro Area interest rates), Slovenian variables largely beyond policy makers' control (population), and Slovenian policy instruments (tax rates, various government spending items).

For the interest rates we assume that the ECB will not start to raise its policy rates, until 2018; hence the three-month Euribor is assumed to become positive only in 2018. Afterwards it will gradually rise further, reaching $2 \%$ in 2023 and staying at this level until the end of the simulation period. At present, it is expected that US macroeconomic policies will be more expansionary than those in the EU and that the Federal Reserve will increase its discount rate earlier than the ECB. Furthermore, due to the expectation of an expansionary fiscal policy in the US under the current administration, long-term interest rates have already started to rise in the US but also globally. Therefore, the Euro Area long-term interest rate is assumed to rise gradually from 2017 onwards, reaching 4\% from 2025 onwards. The exchange rate between the euro and the US dollar is held constant at 1.10 dollar per euro. For world trade, growth rates are assumed of $1.1 \%$ in $2016,1.8 \%$ in 2017, and 3\% from 2018 onwards. After a decline of 
$18.5 \%$ in 2016 (annual average), the oil price is assumed to rise by $26 \%$ in 2017 , by $10.5 \%$ in 2018 , and by $2.0 \%$ p.a. thereafter.

According to existing projections, Slovenia's working-age population will decline by around $0.75 \%$ per year until 2022 , by $0.5 \%$ in 2023 and by $0.4 \%$ per year afterwards. Conversely, as is the case all over Europe, the population aged 65 and over will continue to rise. According to population projections, this growth will decrease slightly and more or less steadily from almost 3\% per annum in 2016 to $1.6 \%$ in 2030 .

Turning to the fiscal policy instruments, we assume that the tax and social security contribution rates will not be changed from their 2015 values, with the exception of the value added tax rate, which was raised from 20 to $22 \%$ in 2016 . In the baseline, it remains constant at $22 \%$ over the entire simulation period. Government consumption, public investment in equipment and machinery, public spending on R\&D transfer payments to private households, as well as residual government expenditures and revenues are all assumed to increase by $3.5 \%$ p.a. from 2017 until the end of the simulation period. For 2016, the assumed development of the policy instruments and the other exogenous variables aims at matching actual developments as far as possible, to the extent that the data are already available.

These settings of the exogenous variables lead to the following baseline simulation results until 2030. According to recent forecasts (IMAD ${ }^{1} 2016$, European Commission 2017), real GDP in Slovenia increased by about $2.5 \%$ in 2016, and growth will reach around 3\% in 2017 and in 2018. Our model projects real GDP growth of $2.5 \%$ in $2017,3.0 \%$ in 2018 and $2.8 \%$ in 2019. Projected GDP growth then declines to $1.6 \%$ in 2023 and 2024. Afterwards, growth picks up again and stabilises at around $2 \%$ per year. Due to the projected population decline and the slightly lower GDP growth, employment is forecast to decline after 2020. However, due to the decreasing labour force, the unemployment rate will also decline from $8.4 \%$ in 2016 to $2.8 \%$ in 2030 . After negative and then zero inflation until 2018 , the inflation rate is forecast to rise slightly to $1.4 \%$ in 2024 and 2025 , before it declines again to $1.2 \%$ p.a. in the last three years of our simulation period. Despite the overall favourable real economic development, the ratio between public debt and nominal GDP is projected to rise from $83 \%$ in 2016 to $123 \%$ in the final year of the simulation period. This increase is partly attributable to the low inflation, but the main driver of this development is the fact that our model predicts that total government expenditures will rise faster than revenues.

Our model predicts a rather pessimistic development of the trend total factor productivity. According to the simulation, trend TFP would stagnate on average between 2017 and 2030. As we regard this as being too pessimistic, we exogenously raised trend TFP via an add factor such that it increases by $1.6 \%$ per year on average during the simulation period. Furthermore, with the aim of strengthening potential GDP growth we reduced the non-accelerating inflation rate of unemployment (NAIRU). According to the recent forecast by the European Commission, the Slovenian NAIRU will decrease from $7.0 \%$ in 2016 to $6.0 \%$ in

\footnotetext{
${ }^{1}$ IMAD is the Institute of Macroeconomic Analysis and Development of the Republic of Slovenia.
} 
2025. For our simulations we assumed a more pronounced decrease to $4.0 \%$ in 2025 and to $0.5 \%$ in 2030 .

\section{Can Growth in Slovenia be Boosted by Means of Fiscal Policies?}

In this section we run three alternative simulations with different policy mixes during the period 2017 to 2030 . We again distinguish between four spending instruments and three tax rates. In addition, we analyse the effects of an increase in the share of people with tertiary education in the labour force. We subsume this instrument under spending measures, although due to the lack of adequate data our model does not contain a specific instrument which is directly related to the education level, such as the number of teachers at high schools or the amount of public spending on universities.

For the simulations we consider the following instruments:

(i) $G N$ :

Government consumption, nominal

(ii) TRANSFERS:

Transfers, nominal

(iii) GINVN:

Public investment, nominal

(iv) GERD:

Government expenditures on $\mathrm{R} \& \mathrm{D}$, nominal

(v) LFTER:

Share of people with tertiary education in the labour force

(vi) VAT:

Value added tax rate

(vii) INCTAX:

Personal income tax rate

(viii) SOCEMP:

Employees' social security contribution rate

(ix) REVREST:

Other government revenues

The changes in the fiscal policy instruments with respect to the baseline are summarized in Table 1 (scenario S1), Table 2 (scenario S2) and Table 3 (scenario $\mathrm{S} 3$ ). The tables show deviations in a particular instrument variable from baseline values in percent or percentage points. Changes in LFTER, INCTAX, SOCEMP and VAT are measured as percentages points, while changes in all other variables are measured as percentages. We defined the policy measures of the expenditure aggregates in absolute terms, i.e. in million euros; hence, the percentage deviations as shown in the tables were calculated endogenously.

Scenario S1 is characterised by increases in public investment, both in equipment and construction and in the education of the work force. Furthermore, government consumption and transfers to private households increased. These higher expenditures are financed by increasing "other" revenues, namely revenues from taxes without direct effects on aggregate demand, such as property taxes (or, ideally, "lump-sum" taxes). Here we consider an expansionary (Keynesian) fiscal policy mix of moderately higher expenditures distributed proportionately over expenditure categories and financed in part by higher taxes with only indirect restrictive effects.

In scenario S2, we shift public expenditures from "unproductive" public consumption and transfers to "productive" expenditures on R\&D and increase the share of people with tertiary education. Moreover, we assume reductions in income tax rates and social security contributions (both from employees and 
Table 1 Fiscal policy measures in scenario S1

\begin{tabular}{llllllllll}
\hline & GERD & GINVN & GN & TRANSFERS & REVREST & LFTER & INCTAX & SOCEMP & VAT \\
\hline 2018 & $0 \%$ & $0 \%$ & $0 \%$ & $0 \%$ & $0 \%$ & 0.0 & 0.00 & 0.00 & 3.0 \\
2019 & $0 \%$ & $0 \%$ & $0 \%$ & $0 \%$ & $0 \%$ & 0.0 & 0.00 & 0.00 & 3.0 \\
2020 & $2 \%$ & $2 \%$ & $2 \%$ & $2 \%$ & $0 \%$ & 0.1 & 0.00 & 0.00 & 3.0 \\
2021 & $4 \%$ & $4 \%$ & $4 \%$ & $4 \%$ & $0 \%$ & 0.2 & 0.00 & 0.00 & 3.0 \\
2022 & $6 \%$ & $6 \%$ & $6 \%$ & $6 \%$ & $0 \%$ & 0.3 & 0.00 & 0.00 & 3.0 \\
2023 & $8 \%$ & $8 \%$ & $8 \%$ & $8 \%$ & $41 \%$ & 0.4 & 0.00 & 0.00 & 3.0 \\
2024 & $11 \%$ & $11 \%$ & $11 \%$ & $11 \%$ & $48 \%$ & 0.5 & 0.00 & 0.00 & 3.0 \\
2025 & $15 \%$ & $15 \%$ & $15 \%$ & $15 \%$ & $55 \%$ & 0.6 & 0.00 & 0.00 & 3.0 \\
2026 & $19 \%$ & $19 \%$ & $19 \%$ & $19 \%$ & $62 \%$ & 0.7 & 0.00 & 0.00 & 3.0 \\
2027 & $23 \%$ & $23 \%$ & $23 \%$ & $23 \%$ & $69 \%$ & 0.8 & 0.00 & 0.00 & 3.0 \\
2028 & $28 \%$ & $28 \%$ & $28 \%$ & $28 \%$ & $76 \%$ & 0.9 & 0.00 & 0.00 & 3.0 \\
2029 & $34 \%$ & $34 \%$ & $34 \%$ & $34 \%$ & $83 \%$ & 1.0 & 0.00 & 0.00 & 3.0 \\
2030 & $41 \%$ & $41 \%$ & $41 \%$ & $41 \%$ & $90 \%$ & 1.1 & 0.00 & 0.00 & 3.0 \\
\hline
\end{tabular}

The table shows deviations from the baseline in percent or percentage points

employers) in order to provide incentives for higher employment. This scenario can be interpreted as a "supply-side" fiscal policy, aiming at (1) simultaneously strengthening aggregate demand and aggregate supply in the goods market (potential output) and (2) increasing employment by reducing the tax wedge in the labour market (i.e., the average income tax rate and the social security

Table 2 Fiscal policy measures in scenario S2

\begin{tabular}{llllllllll}
\hline & GERD & GINVN & GN & TRANSFERS & REVREST & LFTER & INCTAX & SOCEMP & VAT \\
\hline 2018 & $136 \%$ & $7 \%$ & $-2 \%$ & $-1 \%$ & $9 \%$ & 0.5 & -0.25 & -0.25 & 3.0 \\
2019 & $263 \%$ & $13 \%$ & $-3 \%$ & $-3 \%$ & $18 \%$ & 0.8 & -0.50 & -0.50 & 3.0 \\
2020 & $382 \%$ & $19 \%$ & $-4 \%$ & $-4 \%$ & $26 \%$ & 1.0 & -0.75 & -0.75 & 3.0 \\
2021 & $492 \%$ & $24 \%$ & $-6 \%$ & $-5 \%$ & $33 \%$ & 1.3 & -1.00 & -1.00 & 3.0 \\
2022 & $594 \%$ & $29 \%$ & $-7 \%$ & $-6 \%$ & $40 \%$ & 1.5 & -1.25 & -1.25 & 3.0 \\
2023 & $689 \%$ & $34 \%$ & $-8 \%$ & $-7 \%$ & $46 \%$ & 1.8 & -1.50 & -1.50 & 3.0 \\
2024 & $776 \%$ & $38 \%$ & $-9 \%$ & $-8 \%$ & $52 \%$ & 2.0 & -1.75 & -1.75 & 3.0 \\
2025 & $857 \%$ & $42 \%$ & $-10 \%$ & $-9 \%$ & $58 \%$ & 2.3 & -2.00 & -2.00 & 3.0 \\
2026 & $932 \%$ & $46 \%$ & $-11 \%$ & $-10 \%$ & $63 \%$ & 2.5 & -2.25 & -2.25 & 3.0 \\
2027 & $1000 \%$ & $49 \%$ & $-11 \%$ & $-10 \%$ & $67 \%$ & 2.8 & -2.50 & -2.50 & 3.0 \\
2028 & $1063 \%$ & $52 \%$ & $-12 \%$ & $-11 \%$ & $71 \%$ & 3.0 & -2.75 & -2.75 & 3.0 \\
2029 & $1120 \%$ & $55 \%$ & $-13 \%$ & $-12 \%$ & $75 \%$ & 3.3 & -3.00 & -3.00 & 3.0 \\
2030 & $1173 \%$ & $58 \%$ & $-13 \%$ & $-12 \%$ & $79 \%$ & 3.5 & -3.25 & -3.25 & 3.0 \\
\hline
\end{tabular}

The table shows deviations from the baseline in percent or percentage points 
Table 3 Fiscal policy measures in scenario S3

\begin{tabular}{llllllllll}
\hline & GERD & GINVN & GN & TRANSFERS & REVREST & LFTER & INCTAX & SOCEMP & VAT \\
\hline 2018 & $136 \%$ & $0 \%$ & $0 \%$ & $0 \%$ & $0 \%$ & 0.5 & -0.13 & -0.13 & 3.0 \\
2019 & $263 \%$ & $0 \%$ & $0 \%$ & $0 \%$ & $0 \%$ & 0.8 & -0.25 & -0.25 & 3.0 \\
2020 & $382 \%$ & $3 \%$ & $2 \%$ & $2 \%$ & $0 \%$ & 1.0 & -0.38 & -0.38 & 3.0 \\
2021 & $492 \%$ & $6 \%$ & $4 \%$ & $4 \%$ & $0 \%$ & 1.3 & -0.50 & -0.50 & 4.0 \\
2022 & $594 \%$ & $9 \%$ & $7 \%$ & $6 \%$ & $0 \%$ & 1.5 & -0.63 & -0.62 & 4.0 \\
2023 & $689 \%$ & $11 \%$ & $9 \%$ & $10 \%$ & $41 \%$ & 1.8 & -0.75 & -0.75 & 4.0 \\
2024 & $776 \%$ & $14 \%$ & $11 \%$ & $12 \%$ & $48 \%$ & 2.0 & -0.88 & -0.88 & 5.0 \\
2025 & $857 \%$ & $16 \%$ & $15 \%$ & $15 \%$ & $55 \%$ & 2.3 & -1.00 & -1.00 & 5.0 \\
2026 & $932 \%$ & $18 \%$ & $19 \%$ & $19 \%$ & $62 \%$ & 2.5 & -1.13 & -1.13 & 5.0 \\
2027 & $1000 \%$ & $20 \%$ & $23 \%$ & $23 \%$ & $69 \%$ & 2.8 & -1.25 & -1.25 & 5.0 \\
2028 & $1063 \%$ & $21 \%$ & $28 \%$ & $28 \%$ & $76 \%$ & 3.0 & -1.38 & -1.38 & 5.0 \\
2029 & $1120 \%$ & $23 \%$ & $34 \%$ & $34 \%$ & $83 \%$ & 3.3 & -1.50 & -1.50 & 5.0 \\
2030 & $1173 \%$ & $24 \%$ & $41 \%$ & $41 \%$ & $90 \%$ & 3.5 & -1.63 & -1.63 & 5.0 \\
\hline
\end{tabular}

The table shows deviations from the baseline in percent or percentage points

contribution rate). These two tax rates are lowered by 0.25 percentage points (pp) with respect to the baseline in 2018, and the deviation from the baseline is increased over time to reach $3.25 \mathrm{pp}$. in 2030. In order to prevent public debt from increasing, these expansionary fiscal policies are financed by reducing public consumption and transfers to private households.

In scenario S3, we drastically increase those public spending items that entail both demand and supply effects, namely public spending on R\&D and fixed capital formation. Both of these spending categories are part of domestic demand, but they also positively influence potential GDP via the capital stock and technical progress. Furthermore, we lower the tax wedge on labour income as in scenario S2 but only by half as much. To deal with the resulting government budget deficit, we assume that the Slovenian government increases the VAT rate to $27 \%$. In addition, the remaining government revenues are increased from around the middle of the simulation period onwards, since otherwise the debt ratio would explode. Here the deviation from the baseline rises from $41 \%$ in 2023 to $90 \%$ in 2030 .

Figures 1-9 show the evolution of some macroeconomic indicators usually relevant for policy makers as well as the general public: real GDP and potential output in million euro at previous year's prices, persons employed, the unemployment rate, the CPI, the inflation rate, net exports in relation to GDP and the public debt to GDP ratio. All figures depict the paths of the relevant variables in the baseline and in the three alternative scenarios (denoted with S1, S2 and S3, respectively).

Comparing the three policy scenarios with the baseline (business as usual) and to each other, we can identify scenario S2 as being the clear winner. It entails sustained higher GDP growth (both actual and potential) than the baseline and scenarios S1 and S3, higher employment and lower unemployment as well as low 


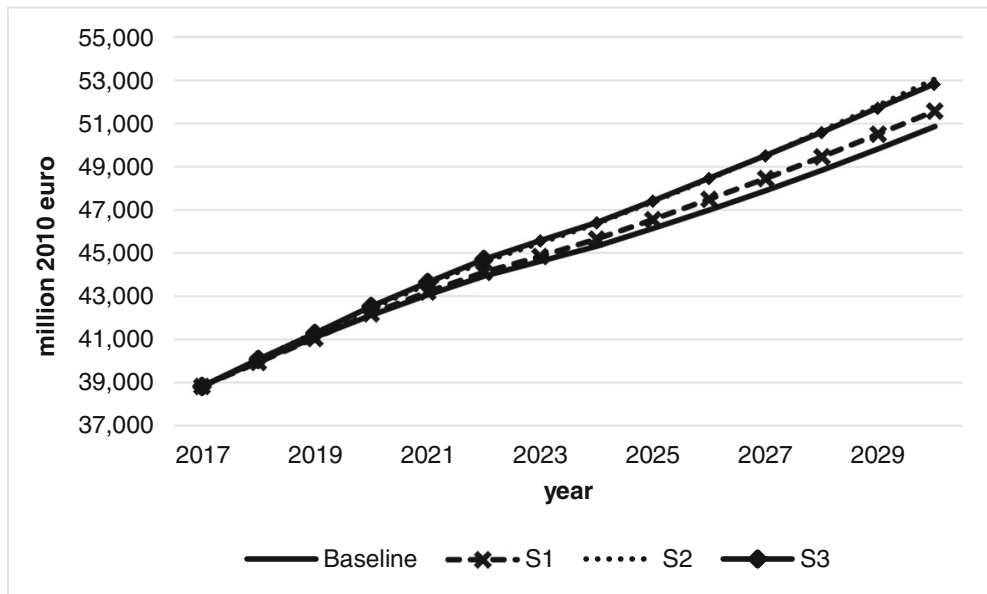

Fig. 1 Real GDP level 2017-2030. Source: Eurostat database (http://ec.europa.eu/eurostat/data/database); authors' calculations and illustration

inflation and, remarkably, the lowest public debt (even a decrease in the debt to GDP ratio by about ten percentage points). At first glance, this result is unexpected as our econometric model is mainly a Keynesian demand-side model where more expansionary effects of increases in expenditures like public consumption and transfers as implemented in scenario S3 might be expected. However, the combination of supply-side policies stimulating productivity growth in the goods market and employment in the labour market lead to supply and demand effects, which bring about virtual full employment without negative side effects on the government budget. Long-run considerations in designing fiscal policies as

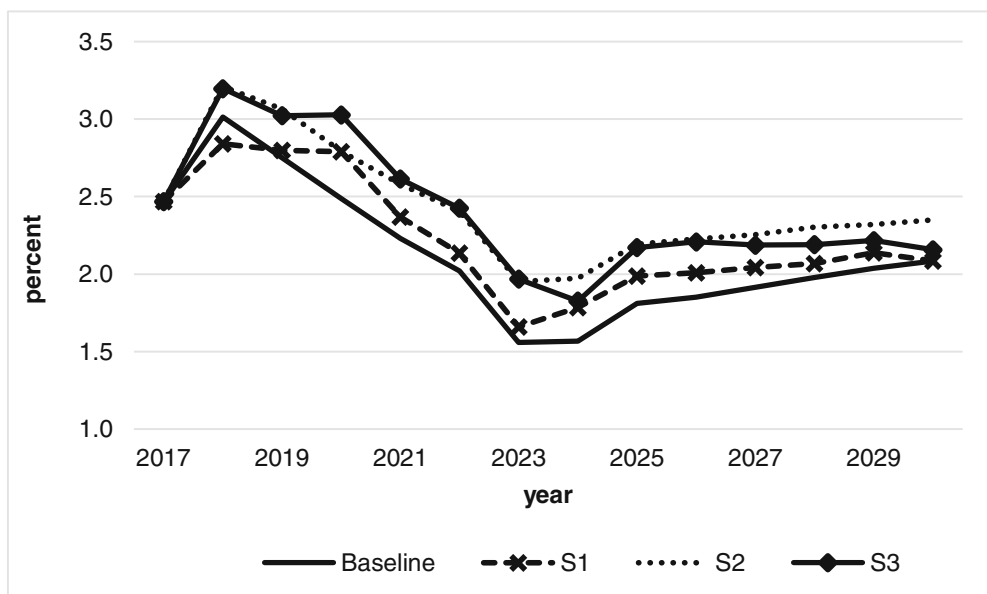

Fig. 2 Real GDP growth 2017-2030. Source: Eurostat database (http://ec.europa.eu/eurostat/data/database); authors' calculations and illustration 


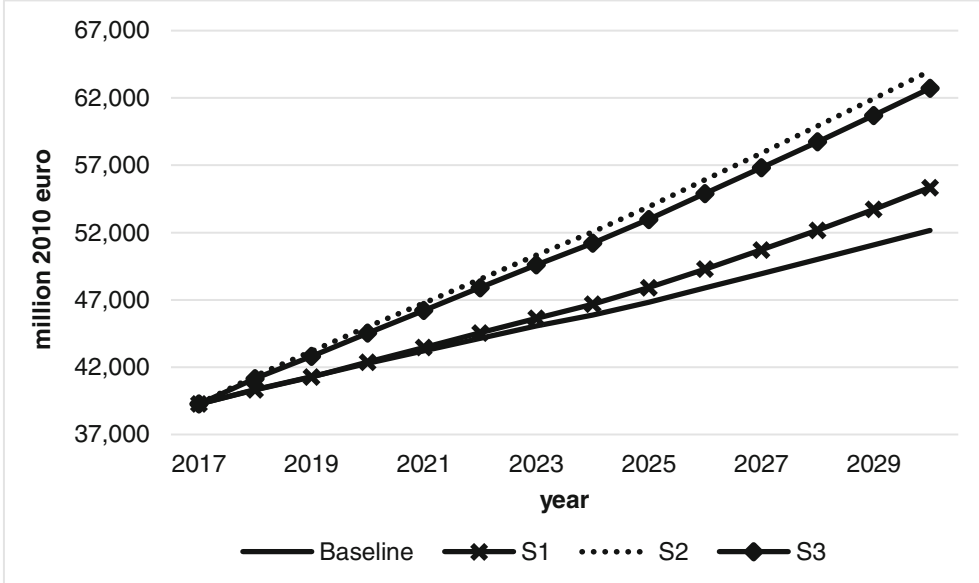

Fig. 3 Potential output 2017-2030. Source: Eurostat database (http://ec.europa.eu/eurostat/data/database); authors' calculations and illustration

suggested by growth theory thus turn out to be adequate as well in dealing with the short- and medium-run problems of stabilizing aggregate demand.

\section{Conclusions}

Slovenia, a small open economy in the Euro Area, was hit particularly hard by the Great Recession and the Euro crisis. A forecast with SLOPOL10, a medium-sized macroeconometric model for Slovenia, predicts moderate economic growth and rising public debt relative to GDP over the next few years. The recent

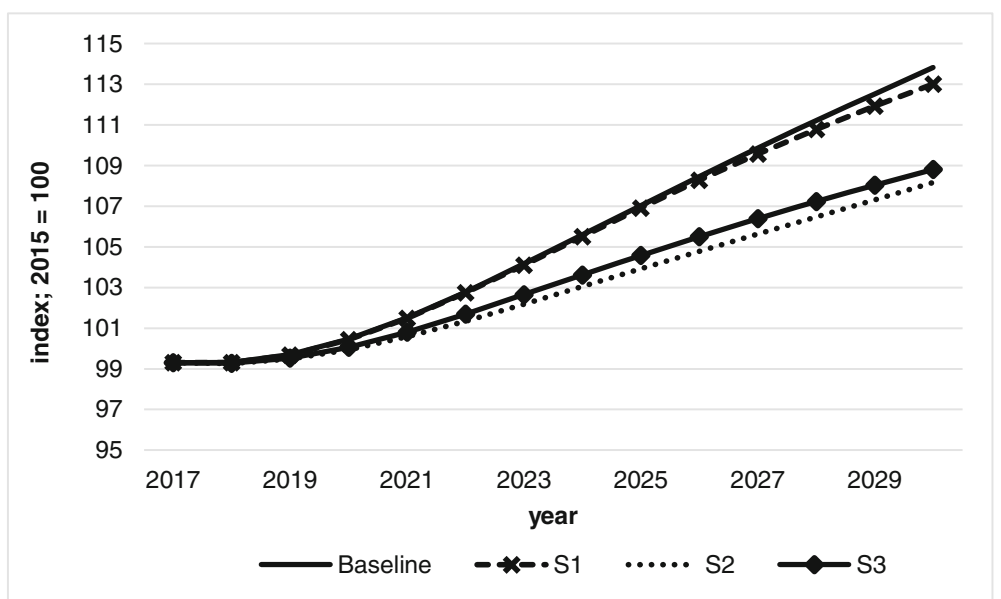

Fig. 4 Consumer price index (CPI) 2017-2030. Source: Eurostat database (http://ec.europa.eu/eurostat/data/ database); authors' calculations and illustration 


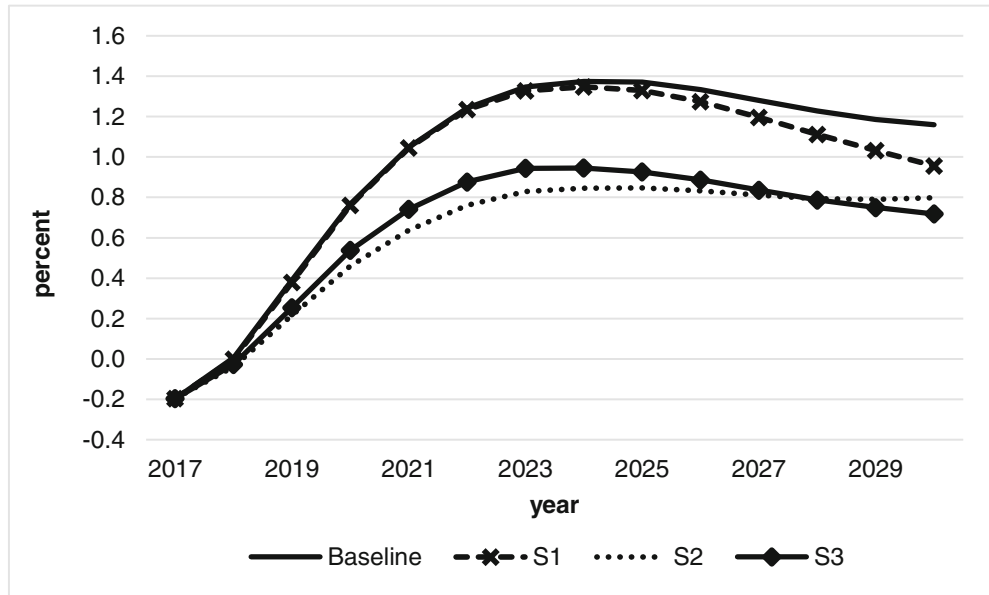

Fig. 5 Inflation rate 2017-2030. Source: Eurostat database (http://ec.europa.eu/eurostat/data/database); authors' calculations and illustration

macroeconomic and fiscal performance and forecast raise the question as to how the economy could be stimulated without simultaneously increasing the debt level (or even with reducing it). We use SLOPOL10 to simulate different expansionary fiscal policy measures on the revenue and expenditure side.

Our results show that those public spending measures that entail both demandand supply-side effects (i.e., public investment and especially spending related to R\&D and tertiary education), are more effective in stimulating real GDP than pure demand-side measures. Measures that improve the education level of the labour

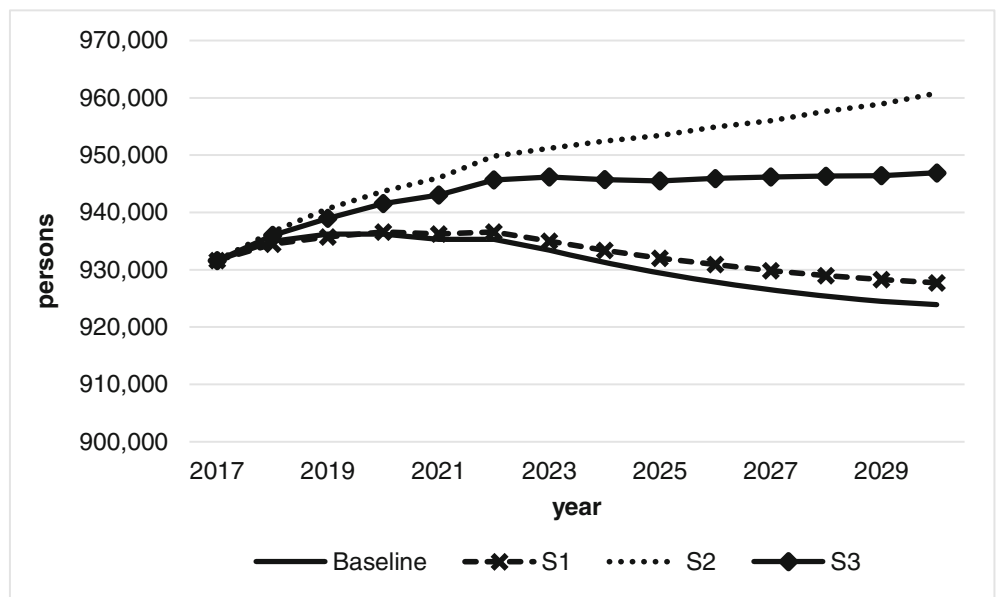

Fig. 6 Employment 2017-2030. Source: Eurostat database (http://ec.europa.eu/eurostat/data/database); authors' calculations and illustration 


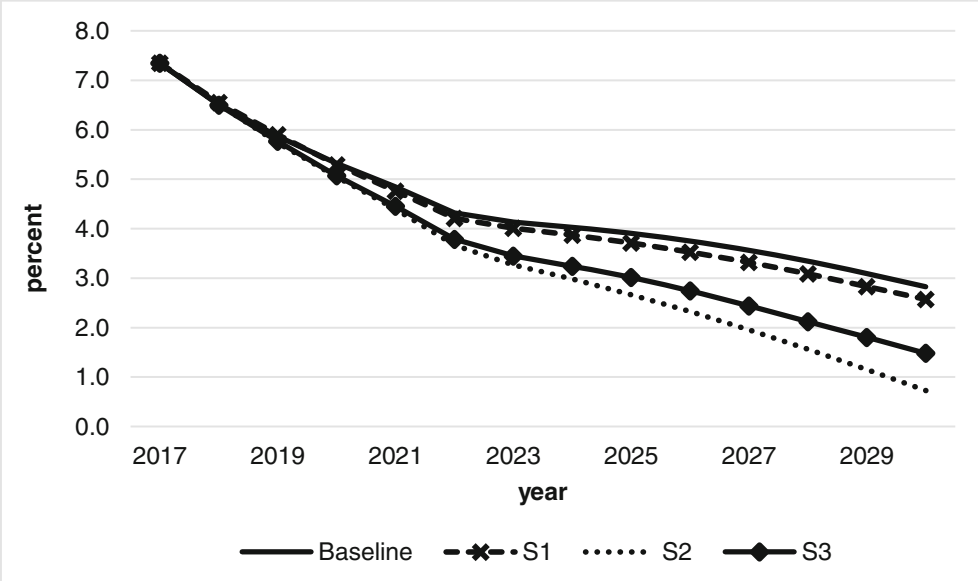

Fig. 7 Unemployment rate 2017-2030. Source: Eurostat database (http://ec.europa.eu/eurostat/data/database); authors' calculations and illustration

force are effective at stimulating potential GDP. Employment can be most effectively stimulated by cutting the income tax rate and the social security contribution rate (i.e., by reducing the tax wedge on labour income and positively affecting Slovenia's international competitiveness). Due to the high elasticity of imports with respect to demand, pure demand-side effects on real variables are small, showing that a small open economy like Slovenia has only very little scope for influencing macroeconomic development with demand management by fiscal policies.

Of course, it would be premature to infer strong conclusions for the current macroeconomic situation of the Slovenian economy based on just one model

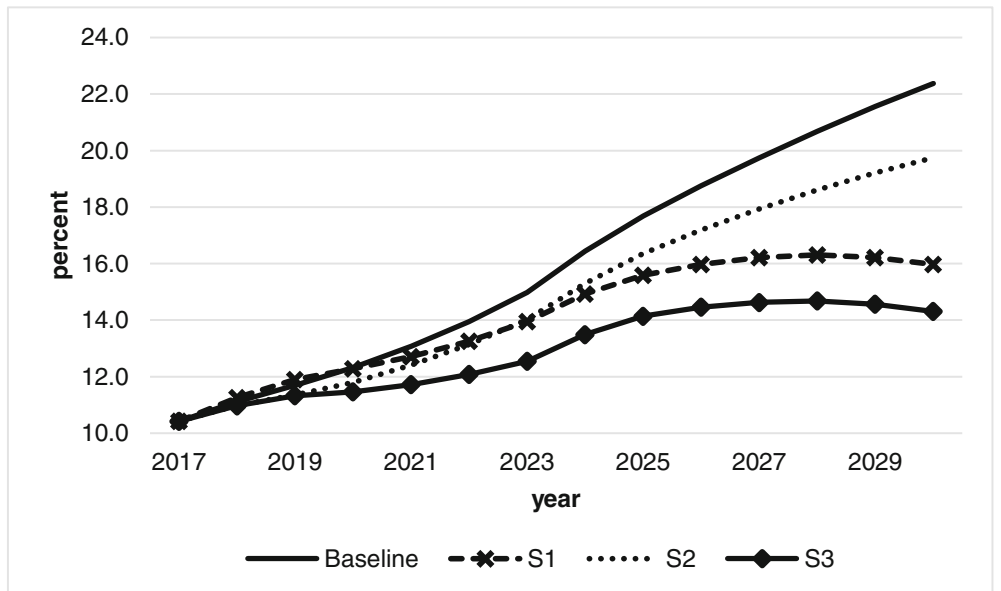

Fig. 8 Net exports in relation to GDP 2017-2030. Source: Eurostat database (http://ec.europa.eu/eurostat/ data/database); authors' calculations and illustration 


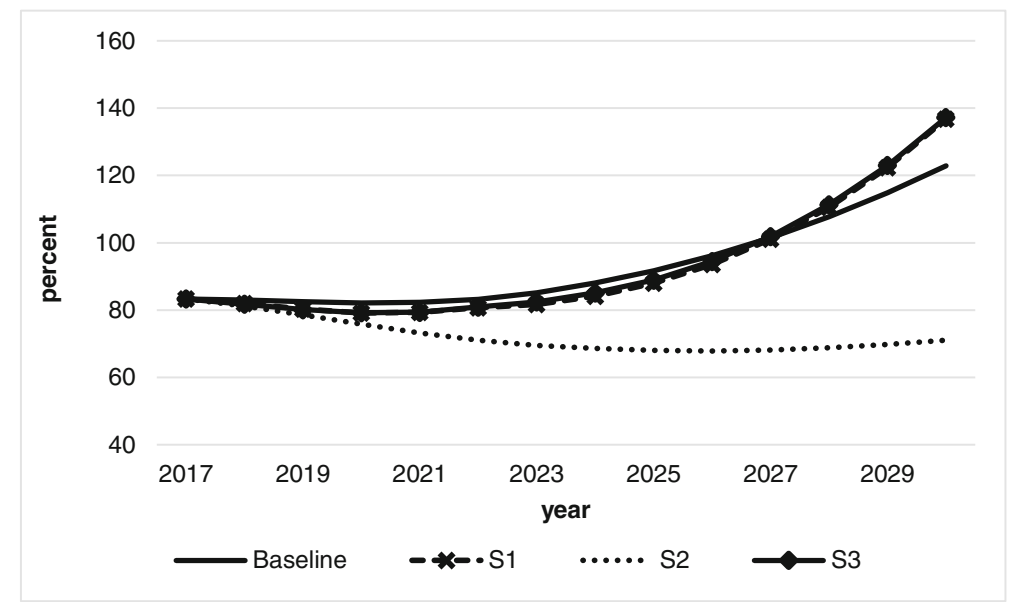

Fig. 9 Public debt to GDP ratio 2017-2030. Source: Eurostat database (http://ec.europa.eu/eurostat/data/ database); authors' calculations and illustration

specification, but our results clearly support the theory and empirical evidence that policy measures strengthening potential GDP entail the best results in terms of stimulating economic growth and employment without putting additional strain on public finances. Supply-side-related fiscal policy measures outmatch those relying solely on demand effects.

Acknowledgments Open access funding provided by University of Klagenfurt. The authors gratefully acknowledge financial support from the Austrian Science Foundation FWF (project no. I 2764-G27) and the Slovenian Research Agency ARRS (contract no. 630-31/2016-1). Comments by an anonymous referee helped improving the paper. The usual caveat applies.

Open Access This article is distributed under the terms of the Creative Commons Attribution 4.0 International License (http://creativecommons.org/licenses/by/4.0/), which permits unrestricted use, distribution, and reproduction in any medium, provided you give appropriate credit to the original author(s) and the source, provide a link to the Creative Commons license, and indicate if changes were made.

\section{References}

European Commission (2017). European economic forecast. Winter 2017. Institutional Paper 048. Brussels. https://ec.europa.eu/info/sites/info/files/ip048_en_4.pdf.

Havik, K., Mc Morrow, K., Orlandi, F., Planas, C., Raciborski, R., Röger, W., Rossi, A., Thum-Thysen, A., Vandermeulen, V. (2014). The production function methodology for calculating potential growth rates and output gaps. European Commission Economic Papers 535, Brussels. http://ec.europa.eu/economy_ finance/publications/economic_paper/2014/pdf/ecp535_en.pdf.

IMAD (2016). Autumn forecast of economic trends 2016. Ljubljana. http://www.umar.gov.si/fileadmin/user upload/napovedi/jesen/aJN2016_za_splet.pdf.

Weyerstrass, K., Neck, R., Blueschke, D., Majcen, B., Srakar, A., Verbič, M. (2018). SLOPOL10: a macroeconometric model for Slovenia. Economic and Business Review 20, forthcoming. 